\title{
CSSR2019
}

6th International Conference on Science \& Social Research 2019

https://cssr.uitm.edu.my/2019/

Parkroyal Penang Resort, Batu Ferringhi, Pulau Pinang, Malaysia, 04-05 Dec 2019

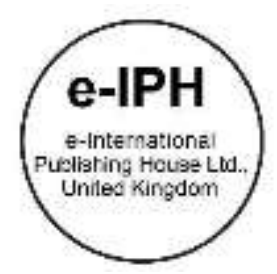

\section{Constructivist Digital Game-Based Learning Courseware for Slow Learners with Numeracy Difficulties}

\author{
Hemanathan Harikrishnan, Noor Dayana Abd Halim, Jamalludin Harun, Shalini Arjunan \\ Department of Educational Science, Mathematics and Creative Multimedia, School of Education, Faculty of Social Science and \\ Humanities, Universiti Teknologi Malaysia, Skudai 81310, Malaysia \\ hemantatashini@gmail.com, noordayana@utm.my, p-jamal@utm.my \\ Tel of 1st Author: 0174951715
}

\begin{abstract}
DGBL is a suitable tool for teaching slow learners, as it allows them to engage actively and practice DGBL Courseware as a learning tool. This paper aims to identify slow learners' difficulties in Mathematics. The develop a DGBL Courseware incorporating Constructivism principles and Engagement Game-Based Elements by Prensky. The research method focuses on following stages: requirement analysis, design and development, including alpha testing by validation from experts, and beta testing, which is user acceptance test to support the efficiency and effectiveness of the Courseware for further improvement.
\end{abstract}

Keywords: Constructivism, Digital Game-Based Learning, Slow Learners, Mathematics

eISSN: 2398-42870 2021. The Authors. Published for AMER ABRA CE-Bs by e-International Publishing House, Ltd., UK. This is an open access article under the CC BYNC-ND license (http://creativecommons.org/licenses/by-nc-nd/4.0/). Peer-review under responsibility of AMER (Association of Malaysian Environment-Behaviour Researchers), ABRA (Association of Behavioural Researchers on Asians/Africans/Arabians) and CE-Bs (Centre for Environment-Behaviour Studies), Faculty of Architecture, Planning \& Surveying, Universiti Teknologi MARA, Malaysia.

DOI: https://doi.org/10.21834/ebpj.v6iSI4.2904

\subsection{Introduction}

In the 21st century, rapid technology changes trigger learners to adapt and play smartphone games (Yang, Li, \& Lu, 2015). The games in smartphones exist in educational games and non-educational games (Volk et al., 2017). Educational games mainly integrate learning materials such as cards, puzzles, matching and crossword in digital format (Khamparia \& Pandey, 2018). Thus, technological utilization in education is not new for learners (Boot et al., 2008). To optimize learning in the classroom, educationists might need to incorporate Digital Game-based Learning (DGBL) with relevant learning theories and strategies to enhance learners' engagement and understanding in learning (Karimi \& Lim, 2010).

\subsection{Literature Review}

A Remedial Programme in Malaysia established by the Ministry of Education in 1988 (Fong, 2018). The programme aimed to reach $100 \%$ literacy and Numeracy by primary school learners getting 9 years old in Malaysia (Roslan Kadri, 2014). The programme aimed to ensure all children master reading, writing, and arithmetic skills (Jong et al., 2015). These skills become core skills for learners before getting more advanced technical and scientific subjects (Lim \& Leong, 2017). Failure in mastering the above essential skills would lead to learners' low achievement and engagement in learning (Lim \& Leong, 2017). Following that, DGBL is a student-centred teaching method which benefits the learners. DGBL is suitable for teaching slow learners with learning difficulties, as it allows them to actively

eISSN: 2398-4287@ 2021. The Authors. Published for AMER ABRA cE-Bs by e-International Publishing House, Ltd., UK. This is an open access article under the CC BYNC-ND license (http://creativecommons.org/licenses/by-nc-nd/4.0/). Peer-review under responsibility of AMER (Association of Malaysian Environment-Behaviour Researchers), ABRA (Association of Behavioural Researchers on Asians/Africans/Arabians) and cE-Bs (Centre for Environment-Behaviour Studies), Faculty of Architecture, Planning \& Surveying, Universiti Teknologi MARA, Malaysia.

DOI: https://doi.org/10.21834/ebpj.v6iSI4.2904 
engage and practice DGBL (Chen, 2017). Game-based learning is a teaching approach practised in the classroom to foster students' understanding of learning topics (Kumar Bhowmik, 2018).

\subsection{Purpose of The Study}

This paper focuses on the early stage of the project-analysis, design/development, and testing phase. However, this paper uncovers the implementation phase of the project. To execute the Remedial Programme in schools, the Ministry of Education Malaysia has listed 13 topics to be mastered by learners before proceeding into Standard 4 . The topics are whole numbers up to 10 , whole numbers up to 20, Addition up to 10, Addition up to 18, Subtraction within 10, Subtraction within 18, Money, Time, Length, Mass, Volume of liquid, Three-Dimensional Shape, and Two-Dimensional Shape (KPM, 2019). All the learning topics interrelate each other. Even though most learners manage to count or identify the numbers, some learners still struggle to perform basic mathematics operations. Hence, the primary concern of this research is to identify difficult topics in lower primary Mathematics education, explore the specific difficulties in mastering the subject of learning, to design, and to develop a game-based courseware based on the complicated topics by integrating constructivism learning principles (Vygotsky, 1978) and engagement game-based elements (Prensky, 2012). Finally, would conduct alpha testing and beta testing to support the suitability and acceptability of the DGBL Courseware.

\subsection{Methodology}

This study aimed to develop DGBL Courseware as a learning tool for Primary Mathematics education among slow learners. One district from Johor, Malaysia, has been selected for this research. The district was chosen because of the high number of innumerate learners in Mathematics and school is equipped with a computer lab. Based on Remedial data in LINUS portal, selected school A for this study to identify the needs and difficulties in numeracy learning. It was enabled the researchers to implement user acceptance test after customizing a DGBL Courseware. A total of 103 learners from standard 2 participated in this study. The learners tested on 13 learning topics, following Standard 2 Mathematical syllabus. Based on the 13 learning topics, Addition and subtraction identified as difficult topics due to the high number of learners' failing in mastering these two operational skills. A total of 52 slow learners were noted to have failed in learning addition and subtraction topics (see Table 1). Content experts validated the test before implementation. After that, the researchers collected various information related to learners' difficulties in acquiring Mathematics skills before designing and developing DGBL Courseware. Then, the prototype for the learning courseware was constructed, and the Courseware was designed and developed using 3D Unity Software. During the design and development phase, the researchers adapted constructivism learning principles and engagement game-based elements proposed by Prensky (2012). Finally, the Courseware was evaluated by adapting user acceptance testing to support the efficiency and effectiveness of the Courseware for further improvement.

\subsection{Result and Discussion}

\subsection{Requirement Analysis}

Preliminary Mathematical Performance Test contains 13 learning topics listed in the Remedial Mathematical Curriculum for lower primary. The test, adapted from Remedial Instrument, is customized by the National Remedial Education Board. Each learning topic has 5 questions. Therefore, the overall test consists of 65 questions. The participants are considered to master the topic if they answer 4 out of 5 questions correctly. The time to answer the questions is 1 hour 15 minutes. Table 1 shows the number of students and their difficult topics of learning.

Table1: Mathematical Topics and The Number of Learners

\begin{tabular}{|c|c|c|c|c|}
\hline Mathematical Topics & $\begin{array}{l}\text { Number of students } \\
\text { mastering the topic }\end{array}$ & $\begin{array}{l}\text { Percentage } \\
\text { Numeracy }(\%)\end{array}$ & $\begin{array}{l}\text { Number of students } \\
\text { yet to master the } \\
\text { topic }\end{array}$ & $\begin{array}{l}\text { Percentage of } \\
\text { innumeracy }(\%)\end{array}$ \\
\hline Whole Number up to 10 & 103 & 100 & 0 & 0 \\
\hline Whole Numbers up to 20 & 103 & 100 & 0 & 0 \\
\hline Addition up to 10 & 51 & 49.51 & 52 & 50.42 \\
\hline Addition up to 18 & 51 & 49.51 & 52 & 50.42 \\
\hline Subtraction within 10 & 51 & 49.51 & 52 & 50.42 \\
\hline Subtraction within 18 & 51 & 49.51 & 52 & 50.42 \\
\hline Money up to RM 10 & 60 & 58.25 & 43 & 41.75 \\
\hline Time & 81 & 78.64 & 22 & 21.36 \\
\hline Length & 55 & 53.40 & 48 & 46.60 \\
\hline Mass & 58 & 56.31 & 45 & 43.69 \\
\hline Volume of Liquid & 55 & 53.40 & 48 & 46.60 \\
\hline Three-Dimensional Shape & 70 & 67.96 & 33 & 32.04 \\
\hline Two-Dimensional Shape & 70 & 67.96 & 33 & 32.04 \\
\hline
\end{tabular}
$\mathrm{N}=103$

The analysis shows the highest number of learners to face difficulties in these four topics, namely Addition up to 10, Addition up to 18, Subtraction within 10, and Subtraction within 18. 50.42\% of learners failed to acquire basic Addition and subtraction in Mathematics. These are four basic operations in Primary Mathematics Curriculum, namely Addition, Subtraction, Multiplication, and Division. However, 
there are only two basic operations in the remedial education for Standard 2 (Addition and subtraction) in the classroom. This performance test enabled the researchers to identify difficult topics in remedial Mathematics to investigate specific inability in respective learning topics further. Therefore, the findings indicated that slow learners had essential Addition and subtraction problems in Mathematics, making it essential for them to master different basic computation levels. Therefore, the researchers focused on relevant content, strategies, and activities to overcome the 11 types of problem in basic Addition and subtraction.

\subsection{Design and Development of Constructivist DGBL Courseware}

In this phase, Constructivist DGBL was designed and developed to help slow learners master the mathematical problems identified above. The DGBL integrated Constructivism principles, namely, knowledge, meaning, and active learning (Vygotsky, 1978) to facilitate Mathematics learning. Furthermore, the constructivist DGBL Courseware incorporates learner engagement elements by Prensky (2012) such as fun, rules, win, representation, conflict, problem-solving, outcomes and feedback, interactive, play, goal, interact, and adaptive. All these elements were integrated into learning courseware content to retain learners' attention in accomplishing the DGBL Courseware activities. Hence, the upcoming section describes the design and development phase of Constructivist DGBL Courseware.

\subsubsection{Constructivist DGBL Courseware Design and Development}

Figures 1 to 7 show the interfaces of the DGBL Courseware. Users have the option to either learn or play the games. Hence, slow learners can select their preferred learning skills based on their needs. There are two modules in the Constructivist DGBL Courseware: Module 1: Learning Module; and Module 2: Gaming Exercise Module. In the Learning Module, learners will be guided in the form of notes, for them to understand Mathematical concepts. Slow learners can interact with the activities to understand and generalize the symbols in Mathematics.Meanwhile, Module 2 is specially designed to enrich optimal understanding in learning's respective skills. There are two different types of games integrated into the Constructivist DGBL Courseware: Quiz and Match. The games are developed by combining the 12 game-based elements proposed (Prensky, 2012). Thus, Courseware is believed to enhance learners' engagement in learning Mathematics. The games' content is designed to assist with learners' difficulties in Mathematics, especially Addition and subtraction. Upon completing the game activities successfully, learners are expected to master basic addition and subtraction. They will be rewarded with an achievement certificate. Below are several interfaces of the Courseware.

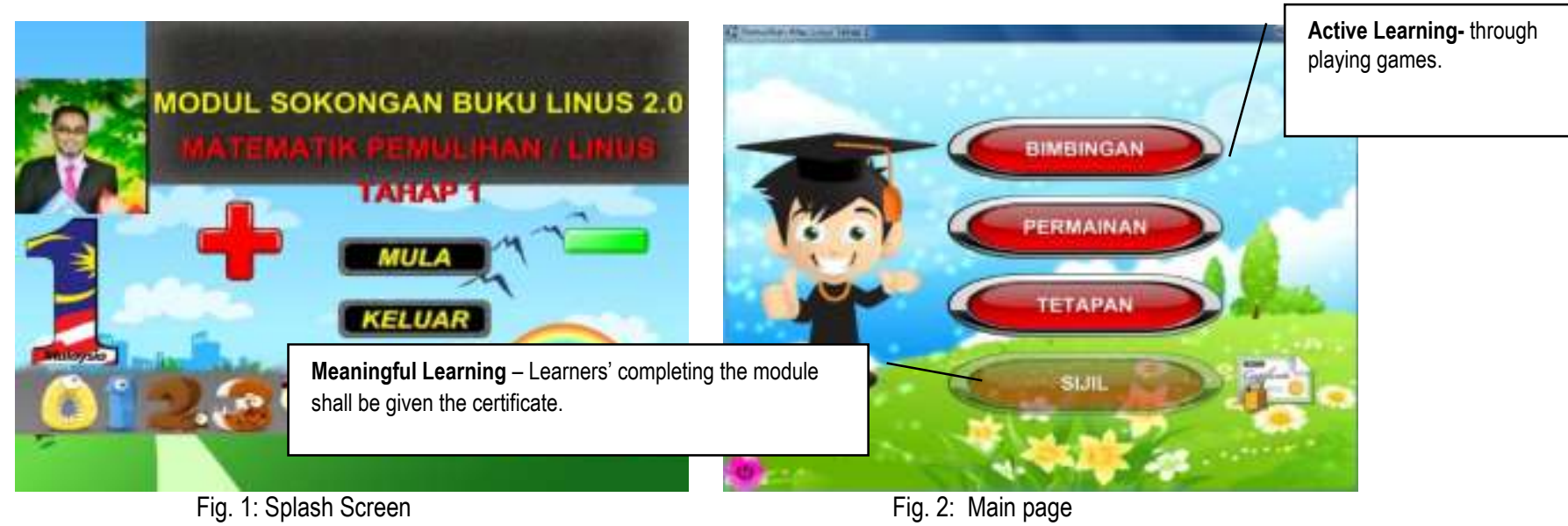

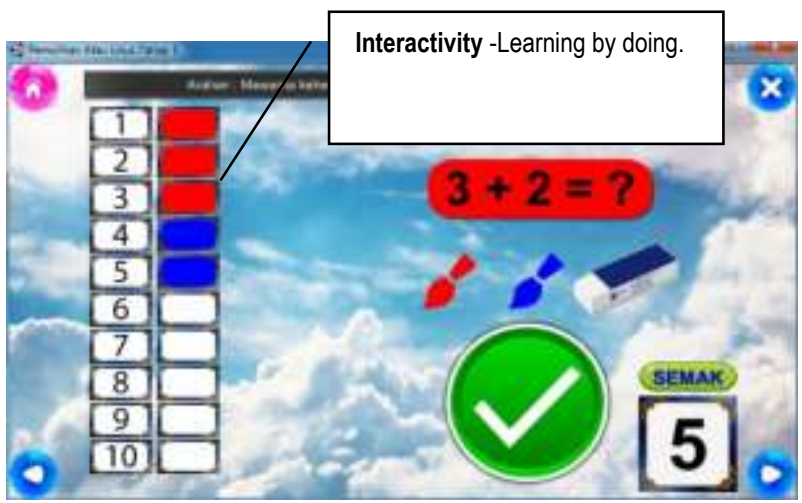

Fig. 3: Learning Module Activities

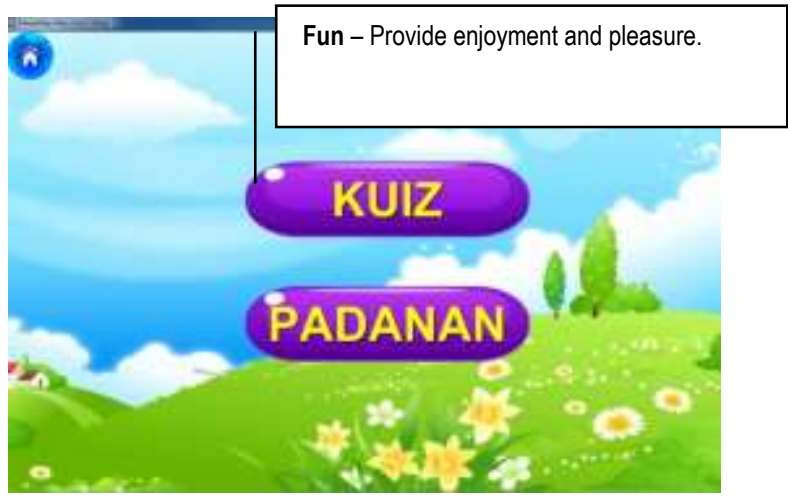

Fig. 4: Game Module Activities

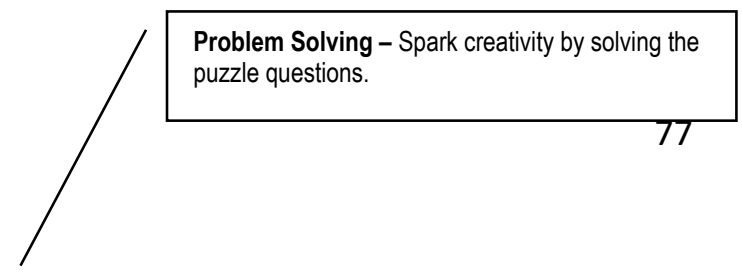




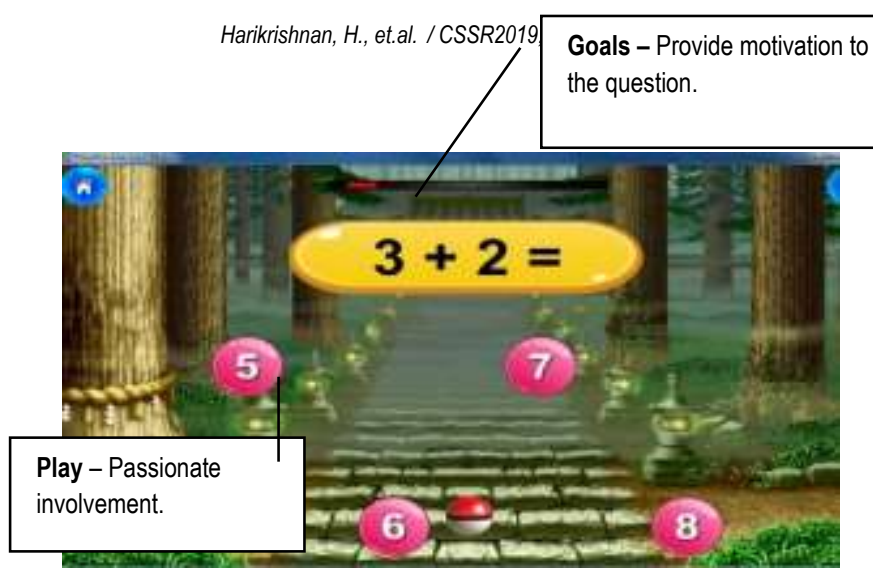

Fig. 5: Quiz Activities

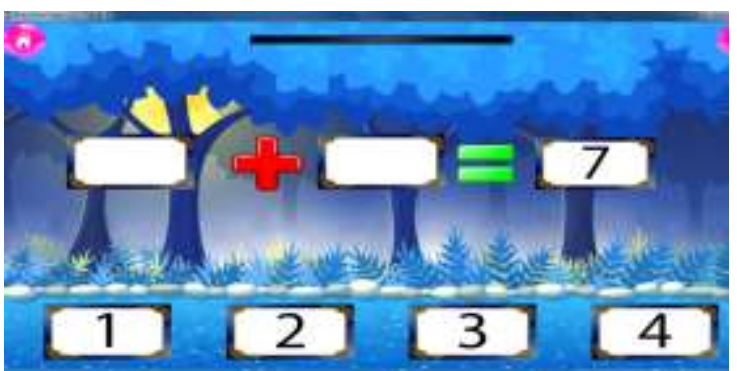

Fig. 6: Matching Activities

\subsubsection{Efficiency}

Efficiency is measured by the users' amount of time in completing the assigned tasks (Kumar Bhowmik et al., 2018). The evaluation on Constructivist DGBL was conducted in School A. Slow learners with difficulties in basic mathematical operations were selected as a sample for this evaluation. Therefore, ten samples were chosen to test the efficiency of the Constructivist DGBL. The samples are labelled A to J. In this test, efficiency testing was conducted by looking at the length of time taken by the users to complete the given exercises. This evaluation aims to measure the length of time the users spent in completing the exercise. If the time spent is short, it indicates that the Courseware is suitable for the users, as they can learn quickly within a short period. Also, qualitative data was also collected on the users' interaction while using Courseware such as text, icon, navigation, button, picture, and sound interaction through observation. This observation helps to detect any arising problem that might occur while using the Courseware, which might affect the users' performance during the learning process. The findings from this session are as follows:

Time Taken: The length of time used by learners to accomplish the activities in the game. The game is split into two activities, the quiz and the match. The exercise in each activity in the game is arranged from easy to difficult. The recorded time includes any mistake made by the user because being one of the drawbacks in learning difficulties; it must be taken into account.

Errors: Mistakes made by users in terms of navigation and interaction while completing the tasks given.

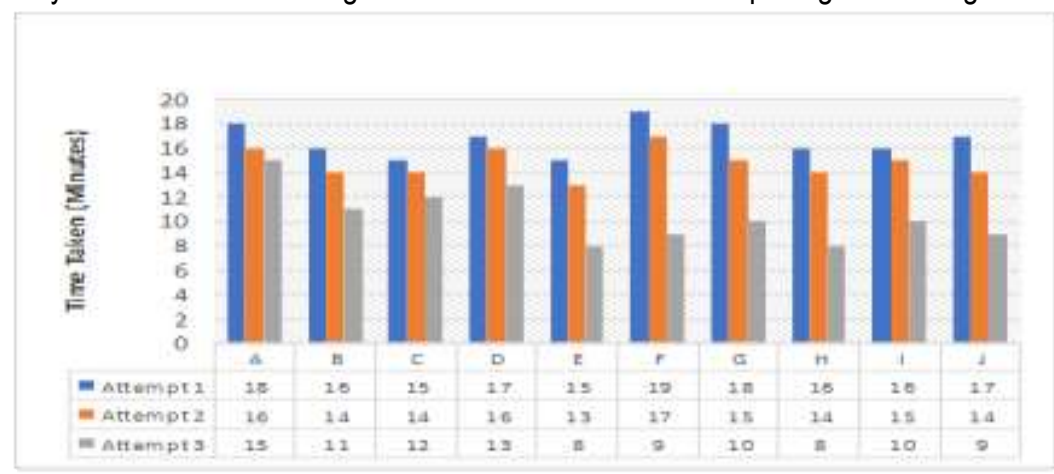

Fig. 7: Time taken for the users to complete the quiz activity

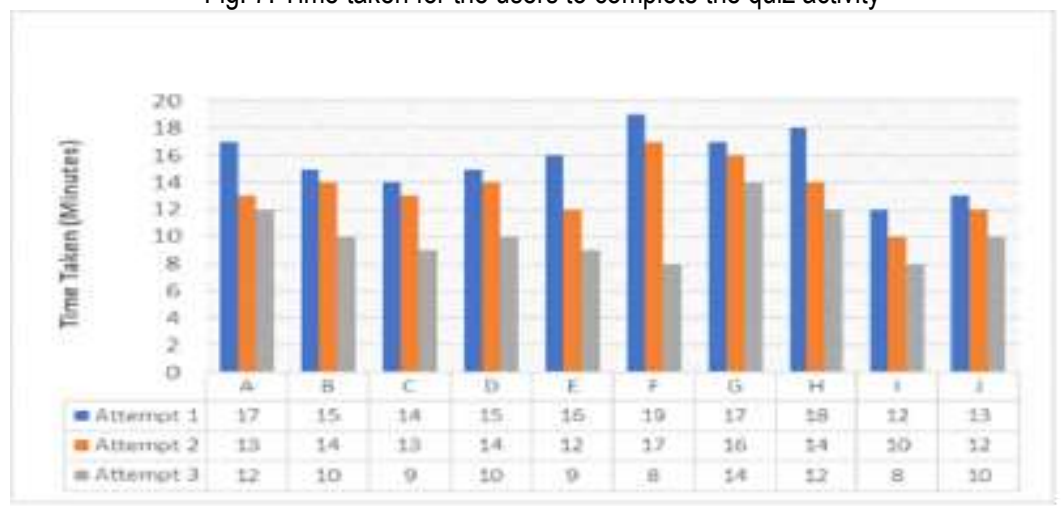

Fig. 8: Time is taken for users to complete the matching activity

The results indicate that the time taken to accomplish the task decreases with the number of attempts performed by the user on similar tasks. Therefore, the designed Constructivist DGBL Courseware is suitable for slow learners, and the interactions developed are appropriate to the speed of performance, so this can strengthen their learning process. 
The second evaluation measured the effectiveness of the Constructivist DGBL Courseware. The researchers compared the developed game with existing teaching practices to evaluate effectiveness. Therefore, based on observation, most of the teachers adapted existing courseware learning modules in teaching slow learners. Thus, the researchers compared the time taken to complete the existing courseware learning modules with the time spent to complete the Constructivist DGBL Courseware. Both modules have similar content and the same exercises, except that the DGBL incorporated gaming theories and elements, as noted earlier. Five slow learners from School A were involved in this evaluation. All the samples have the same problems in teaching basic mathematics operational skills. All the users were required to do one set from each Courseware, and the completion time was recorded.

\section{i. Multimedia Remedial Courseware \\ ii. Constructivist DGBL Courseware}

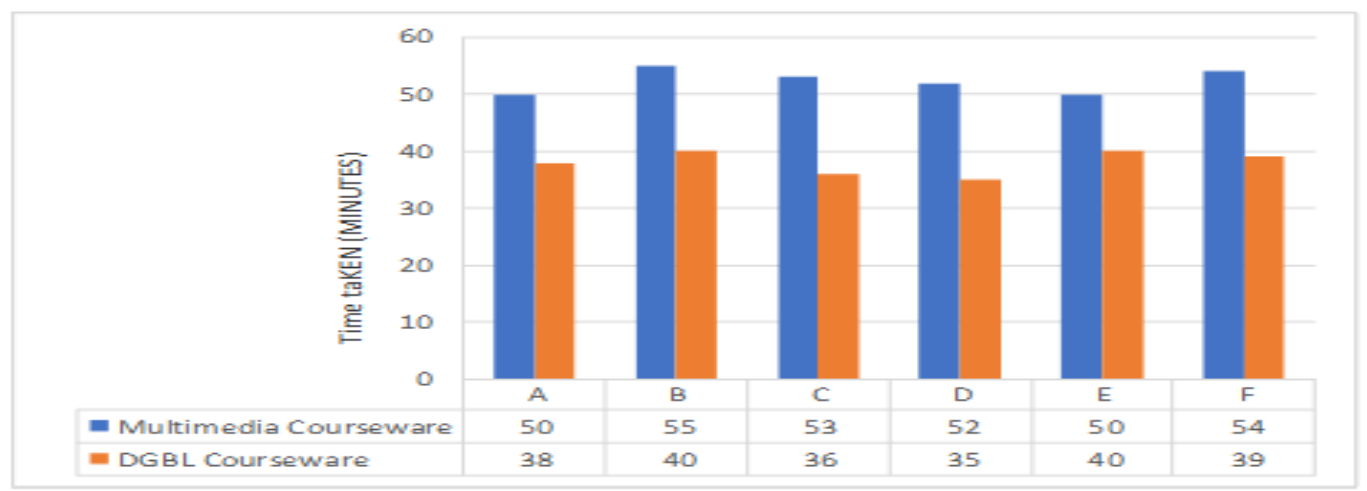

Fig.9: Time is taken for the users to complete the activity in the modules

Figure 9 shows the completion of the exercises by the users in both courseware modules. Based on the findings, users took less time for completing the provided exercises when using Constructivist DGBL, compared to the time taken for completing the Multimedia Courseware. Users displayed more engagement to answer the questions in game-based approaches compared to multimedia approaches. Therefore, Prensky's integration of game-based elements could be an efficient method to facilitate learning in the classroom.

\subsection{Conclusion}

The paper discusses the requirement analysis and development analysis of the Constructivist DGBL Courseware, which will help Slow Learners overcome their difficulties in learning basic Mathematical operations for Numeracy. The integration of learning theories and game-based elements can enhance learners' participation. Thus, it will lead to a better understanding of topics of learning. In summary, the Constructivist DGBL Courseware creates a much more fun learning atmosphere and allows learners to grasp the content of knowledge by retaining their attention. The user acceptance test revealed that DGBL had elevated efficiency and effectiveness compared to the existing learning courseware. Overall, the Constructivist DGBL Courseware evaluation showed that it is suitable as a supplementary learning material for slow learners. It projects a better outcome than discussed above and meets the slow learners' learning needs.

\section{Acknowledgements}

The authors would like to thank Universiti Teknologi Malaysia and Ministry of Higher Education Malaysia to make the project possible. This work was support in making this project possible. This work was supported by the Fundamental Research Grant Scheme (R.J130000, 7831.4F932) initiated by the Ministry of Higher Education.

\section{References}

Adetula, L. O. (2006). Solutions of Simple Word Problems by Nigerian Children: Language and Schooling Factors. Journal for Research in Mathematics Education, 20(5), 489. https://doi.org/10.2307/749422

Boot, W. R., Kramer, A. F., Simons, D. J., Fabiani, M., \& Gratton, G. (2008). The effects of video game playing on attention, memory, and executive control. Acta Psychologica, 129(3), 387-398. https://doi.org/10.1016/j.actpsy.2008.09.005

Carpenter, T. P., Moser, J. M., \& Bebout, H. C. (2006). Representation of Addition and Subtraction Word Problems. Journal for Research in Mathematics Education, 19(4), 345. https://doi.org/10.2307/749545

Del Moral Pérez, M. E., Guzmán Duque, A. P., \& Fernández García, L. C. (2018). Game-Based Learning: Increasing the Logical-Mathematical, Naturalistic, and Linguistic Learning Levels of Primary School Students. Journal of New Approaches in Educational Research, 7(1), 31-39. https://doi.org/10.7821/naer.2018.1.248

Karimi, A., \& Lim, Y. P. (2010). Children, engagement and enjoyment in digital narrative. ASCILITE 2010 - The Australasian Society for Computers in Learning in Tertiary Education, (2001), $\quad 475-483 . \quad$ Retrieved $\quad$ from http:/www.scopus.com/inward/record.url?eid=2-s2.0- 


\section{5\&partnerID=40\&md5=5ffbf45449733fbf1dce396462fc3b75}

Perini, S., Margoudi, M., Oliveira, M. F., \& Taisch, M. (2017). Increasing middle school students' awareness and interest in manufacturing through digital game-based learning (DGBL). Computer Applications in Engineering Education, 25(5), 785-799. https://doi.org/10.1002/cae.21836

Pesare, E., Roselli, T., Corriero, N., \& Rossano, V. (2016). Game-based learning and Gamification to promote engagement and motivation in medical learning contexts. Smart Learning Environments. https://doi.org/10.1186/s40561-016-0028-0

Marc Prensky (2012). "Digital Natives, Digital Immigrants" (PDF). Marcprensky.com.

Roslan Kadri. (2014). Pelaksanaan Program LINUS di sekolah rendah Daerah Muar. Doctoral Dissertation, Universiti Teknologi Malaysia, Faculty of Education, 1-20. https://doi.org/10.1007/s13398-014-0173-7.2 